Maristela Gava

\title{
Viabilidade TÉcnica e Econômica da Produção de Componentes Construtivos Para Habitação Social Utilizando Madeira Serrada de Pinus de Terceira Classe de Qualidade
}

\author{
Dissertação apresentada à Escola de \\ Engenharia de São Carlos, como parte \\ dos requisitos para a obtenção do Título \\ de Mestre em Arquitetura e Urbanismo
}

Orientadora: Profa. Dra. Akemi Ino 
À minha família, meu bem mais precioso. 
AGRADECIMENTOS

"Cada um que passa em nossa vida, passa sozinho, pois cada pessoa é única, e nenhuma substitui a outra.

Cada um que passa em nossa vida, passa sozinho, mas não vai só, nem nos deixa sós: leva um pouco de nós mesmos, deixa um pouco de si mesmo.

Há os que levam muito, mas não há os que não levam nada; há os que deixam muito, mas não há os que não deixam nada.

Esta é a maior responsabilidade da nossa vida e a prova evidente de que duas pessoas não se encontram ao acaso." 
À Profa. Dra Akemi Ino pela orientação e pelo aprendizado, mas principalmente pela amizade que pudemos construir nesses três anos de mestrado;

Ao Prof. Dr. Ioshiaqui Shimbo pela colaboração na pesquisa;

Aos Profs. Drs. José Nivaldo Garcia, Antonio Alves Dias e Carlito Calil Júnior pelo envolvimento e contribuição dados a esta pesquisa;

À Serraria Jaime Medeiros de Engenheiro Maia, Itaberá, SP, que doou a madeira;

Aos colegas do LaMEM, em especial à Elen e ao Johnny pelo apoio na etapa de classificação da madeira e ao Juliano, Jorge e Guilherme pela colaboração nas etapas de produção e ensaio dos painéis;

Aos técnicos do LaMEM: Samuel - que produziu o painel laminado pregado - Arnaldo e Jaime que realizaram os ensaios - e ao Bragatto, da biblioteca;

Ao Facco, técnico do laboratório de Madeiras da ESALQ em Piracicaba, que produziu os painéis laminados cavilhados;

Aos amigos: Paulo de Camargo, Josiane, Juliana Junko, Tatiana Imoto, pela colaboração na etapa de classificação da madeira e produção dos painéis;

Ao Marcelo Cover, que colaborou nos ensaios;

Ao Fernando pela paciência em me responder centenas de vezes as mesmas perguntas e por me ajudar a relembrar as lições de estruturas, aprendidas ainda no curso técnico;

Aos demais integrantes do Grupo de Pesquisa Habis;

À Núbia, minha "vizinha preferida" e minha "secretária particular" :) e à Marininha, uma espécie de "irmã mais nova". Às duas, um carinho todo especial;

À Nagui, uma das mais gratas surpresas em São Carlos, pela amizade, pelo apoio e pela "co-orientação", ainda que extra-oficial;

Ao Renato, pelo carinho e incentivo constantes. Às grandes amizades que pude fazer em São Carlos;

Sobretudo, agradeço a Deus por me proporcionar o convívio com pessoas tão especiais.

Ao ensino público e gratuito e

À FAPESP e ao CNPq pelo suporte financeiro. 
Se não houver frutos, valeu a beleza das flores. Se não houver flores, valeu a sombra das folhas. Se não houver folhas, valeu a intenção da semente. 
RESUMO

GAVA, M. (2005) Viabilidade técnica e econômica da produção de componentes para habitação social utilizando madeira serrada de pinus de terceira classe de qualidade. Dissertação (mestrado em Arquitetura e Urbanismo) - Programa de Pós-graduação em Arquitetura e Urbanismo da Escola de Engenharia de São Carlos - Universidade de São Paulo, São Carlos.

Este trabalho tem como objetivo avaliar a viabilidade técnica e econômica da utilização da madeira serrada de pinus, de terceira classe de qualidade, na produção de componentes para vedação vertical destinados à habitação social, empregando a técnica da laminação vertical cavilhada.

Para o desenvolvimento da pesquisa, foi realizado um estudo de caso, que teve como unidade de análise o Assentamento Rural Fazenda Pirituba, localizado na Região Sudoeste do Estado de São Paulo.

A viabilidade técnica da proposta foi avaliada a partir da produção e experimentação por meios de ensaios exploratórios, de modelos em escala 1:1 e a viabilidade econômica, por sua vez, foi estudada através da simulação de diferentes cenários de produção dos componentes, considerando todas as etapas da cadeia produtiva da habitação em madeira.

Os resultados obtidos com os ensaios exploratórios, indicaram a possibilidade de que a proposta seja tecnicamente viável. Contudo, a simulação de cenários de produção indicou que, para que a mesma seja viável economicamente, torna. se necessária a introdução de políticas públicas que interfiram especialmente na dinâmica da produção de madeira serrada, desde a etapa de plantios, através do estímulo à reposição florestal em pequenas propriedades rurais e uso sustentável dos recursos florestais, passando pela produção, através da introdução de relações de trabalho mais justas, até a comercialização, a partir da expansão do mercado consumidor de produtos de madeira de plantios florestais.

Palavras-chave: habitação social, madeira de terceira, pinus. 
Abstract

This work has as objective to evaluate the technique and economic feasibility of the utilization of the third class sawed wood of pinus in the production of components for vertical seal for social housing, using the vertical wooden dowel lamination technique.

To the development of the research, was realized a study of case that had as unit of analysis the Fazenda Pirituba rural settlement, located in the Southwestern portion of the State of São Paulo, Brazil.

The technique feasibility of the proposal was evaluated through the production and experimentation by exploratories assays in models made in 1:1 scale and the economic feasibility, was studied through the different scenes of production of the components simulation, having considered all the stages of the productive chain of the habitation made by wood.

The gotten results had indicated the possibility that the proposal is technically feasible. However, the scenes of production simulation had indicated that: to the economic fesibility of the proposal, becomes necessary the introduction of public politics that intervene especially in the dinamic of the sawed wooden production, since the stage of plantantion, by the stimulation to the forest replacement in small properties and sustainable use of the forest resources, passing through the production, by the introduction of the works relationship more justs, until the commercialization, from the expansion of the consuming market of the products made by wood from the planted forests.

Key-words: social housing, third class wood, pinus. 
LISTA DE FIGURAS

Figura 1 - Mapa de localização

Figura 2 - Consumo de madeira em toras por segmento industrial.................................... 29

Figura 3 - Balanço entre oferta e demanda de madeira de pinus no Brasil. ............................. 33

Figura 4 . Evolução das importações brasileiras de madeira serrada de Pinus.......................... 34

Figura 5 - Meta de reflorestamento por segmento industrial, prevista no PNF (x1.000ha/ano) .... 37

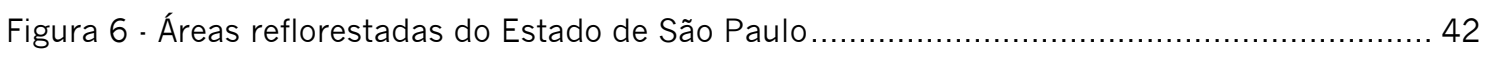

Figura 7 - Áreas reflorestadas com pinus nas Regiões Administrativas do Estado de São Paulo ... 42

Figura 8 - Pólo de Itapeva / Capão Bonito / Buri.....

Figura 9 - Áreas com reflorestamento de Pinus e Eucalyptus dos dez municípios mais expressivos do Pólo de Reflorestamento de Itapeva / Capão Bonito / Buri

Figura 10 - Evolução do reflorestamento no Estado de São Paulo, nos períodos de 1961.62, 1971. 73, 1991.92 e 1999-2000....

Figura 11 - Evolução do reflorestamento (Eucalyptus e Pinus) no Estado de São Paulo. 48

Figura 12 - Níveis de reflorestamento e redução das áreas de plantios de pinus nas Regiões Administrativas analisadas por Kronka et al (2002)....

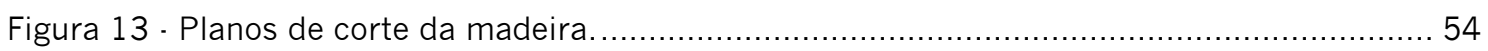

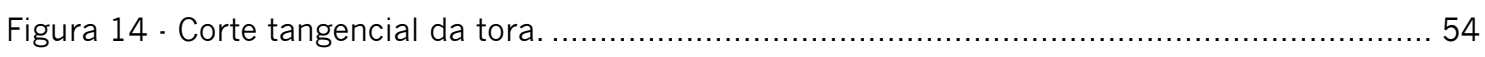

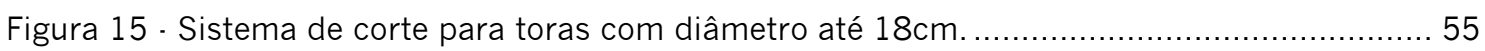

Figura 16 - Sistema de corte para toras com diâmetro igual ou superior a $25 \mathrm{~cm} \ldots \ldots \ldots \ldots \ldots \ldots \ldots 55$

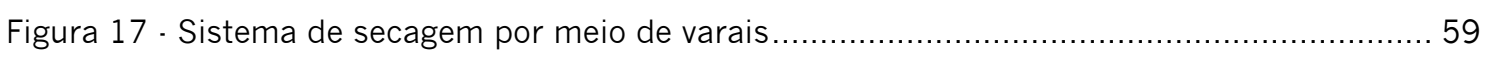

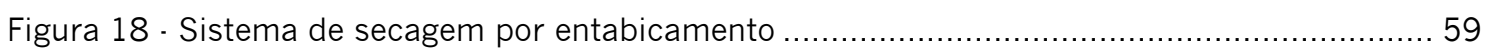

Figura 19 - Forma de armazenamento típico da madeira de terceira nas pequenas serrarias da região de Itapeva, SP.

Figura 20 - Leiaute típico de uma unidade de processamento mecânico da madeira na Região Sudoeste do Estado de São Paulo.

Figura 21 - Aspecto de uma das serrarias pesquisadas na região de Itapeva, onde se observa a utilização de equipamentos ultrapassados, bem como as precárias condições de trabalho dos operários, incluindo a falta de equipamentos de proteção individual. .... 66

Figura 22 - Exemplo das precárias condições de trabalho e das instalações das serrarias pesquisadas na região de Itapeva.

Figura 23 - Resíduos gerados por uma serraria da Região Sudoeste do Estado de São Paulo, em foto tirada no período entre 1998 e 2001.

Figura 24 - Variação dos preços da madeira serrada, vis-à-vis aos preços das toras de pinus para serraria em pé e à inflação.

Figura 25 - Evolução do preço da tora de pinus no mercado doméstico vis-à-vis à inflação no período de janeiro de 2000 a julho de 2003

Figura 26 - Elevação dos preços das toras de pinus no mercado doméstico vis-à-vis a variação cambial no período de janeiro de 2000 a julho de 2003.

Figura 27 - Elevação dos preços das toras de pinus no mercado, vis-à-vis à inflação no período de janeiro a novembro de 2004.

Figura 28 - Elevação dos preços das toras de pinus no mercado, vis-à-vis à variação cambial no período de janeiro a novembro de 2004 ....

Figura 29 - Exemplo de peças com finger-joint..... 
Figura 30 - Diferentes tipos de junta: aparente na lateral (a) e na superfície (b) .....................88

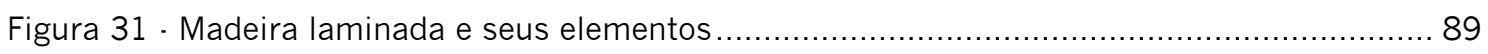

Figura 32 - tipos de laminação: horizontal (a) e vertical (b) ........................................ 89

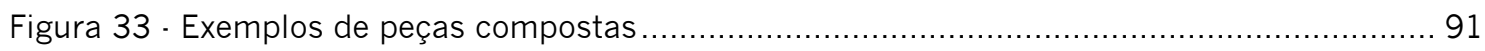

Figura 34 - Projeto de habitação para assentamento rural elaborado pela CDHU.................... 97

Figura 35 - Planta Baixa da unidade habitacional elaborada para uma Agrovila Sustentável, desenvolvida pela equipe do grupo HABIS para a EMBRAPA de São Carlos. .............. 98

Figura 36 - Parcela de custo de materiais, representada pelos diferentes subsistemas e/ou serviços para uma unidade habitacional desenvolvida pela CDHU para assentamento

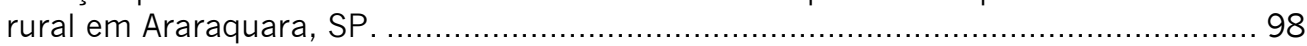

Figura 37 - Parcela de custo de materiais, representada pelos diferentes sub-sistemas e/ou serviços para uma unidade habitacional desenvolvida pelo grupo HABIS para uma Agrovila Sustentável em São Carlos, SP.

Figura 38 - Fluxograma da metodologia de desenvolvimento dos componentes construtivos em madeira de pinus de terceira.

Figura 39 - Distribuição das famílias por faixa de renda ........................................... 104

Figura 40 - Aspecto característico de uma habitação precária do assentamento Rural da Fazenda

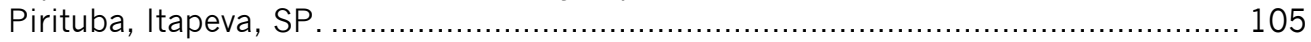

Figura 41 - Distribuição das habitações por material utilizado no sub-sistema de vedação ........ 106

Figura 42 . Composição da população do assentamento por sexo................................... 108

Figura 43 - Distribuição da população por faixa de idade .............................................. 109

Figura 44 - Planta baixa do protótipo a ser construído no Assentamento Rural Fazenda Pirituba, Itapeva, SP.

Figura 45 - Primeiro estudo dos painéis portantes, utilizando o processo de laminação vertical

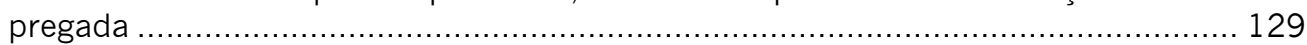

Figura 46 - Projeto do painel laminado cavilhado: Planta Baixa, Vista 1 e Vista 2 ................... 133

Figura 47 . Medição e quantificação da inclinação das fibras ........................................ 139

Figura 48 - Exemplo de nó no centro da face larga .................................................. 140

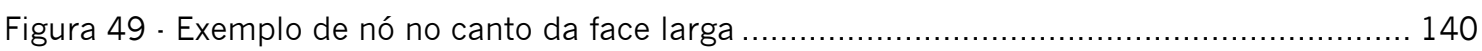

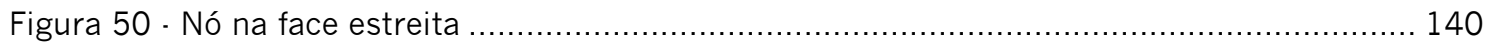

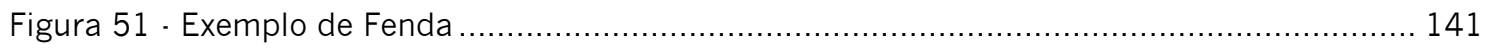

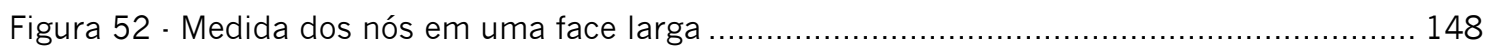

Figura 53 - Medida dos nós em ambas as faces largas ............................................. 148

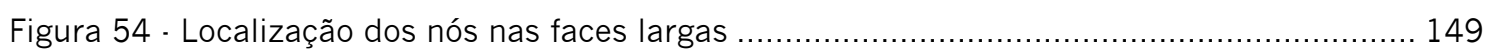

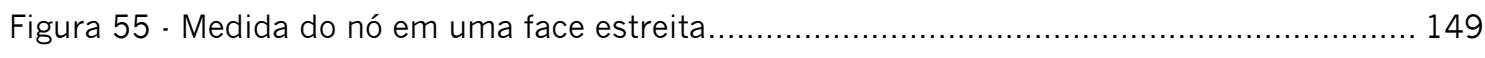

Figura 56 - Medida dos nós que aparecem em uma face larga e uma face estreita ................. 149

Figura 57 . Diferença entre nós individuais (a) e conjunto de nós (b) ................................ 150

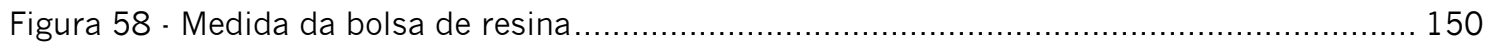

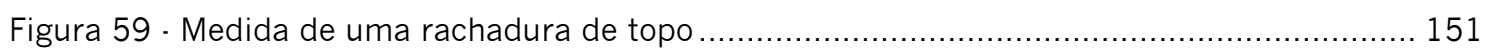

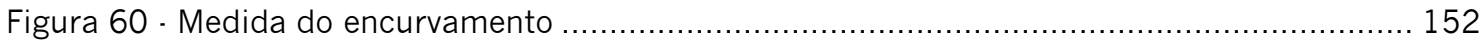

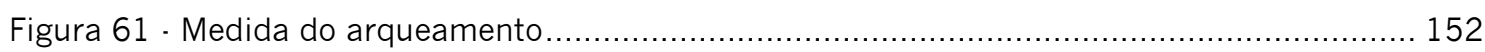

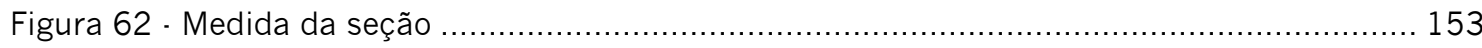

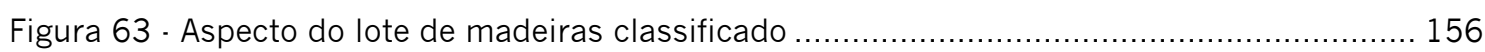

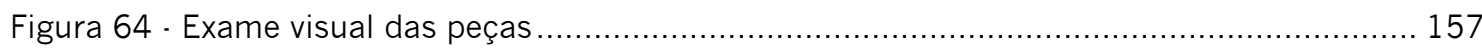

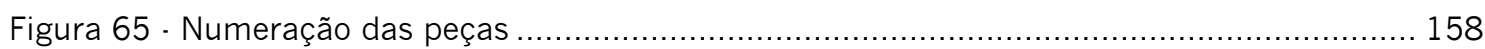


Figura 66 - Esquema de distribuição dos pregos no modelo de painel laminado pregado .......... 160

Figura 67 . Esquema de montagem final do modelo de painel laminado pregado .................... 161

Figura 68 - Modelos de Painéis em Madeira Laminada Cavilhada, produzidos na ESALQ........... 163

Figura 69 - Peças de madeira a serem combinadas inicialmente com esquema de distribuição das

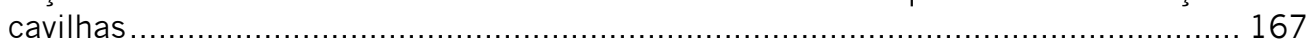

Figura 70 - Combinações possíveis das peças com 60, 90, 150 e 180cm de comprimento e esquema de distribuição das cavilhas previsto........................................ 167

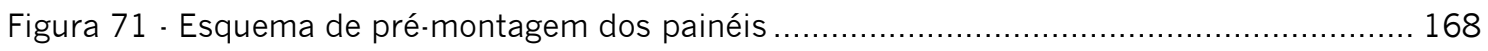

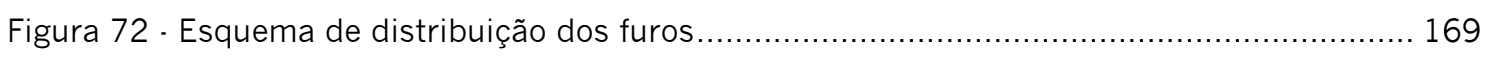

Figura 73 . Esquema de montagem dos painéis laminados cavilhados ............................... 172

Figura 74 - Operações de montagem dos painéis laminados cavilhados: introdução das linhas centrais (a), primeira metade montada (b), montagem da segunda metade (b), paineis

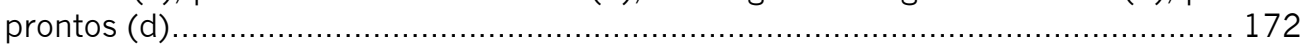

Figura 75 - Esquema das principais forças atuantes no painel: Força de compressão (P) e Empuxo

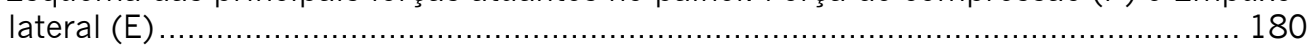

Figura 76 - Esquema da deformação sofrida pelo painel portante, em conseqüência da atuação dos

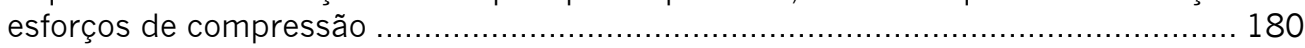

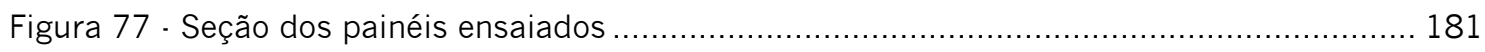

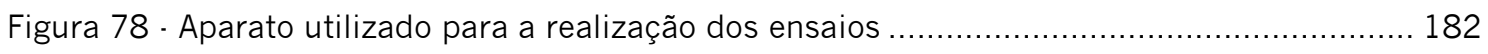

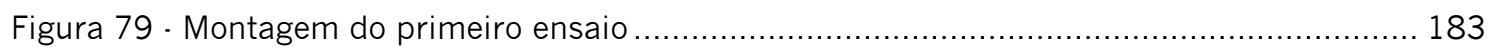

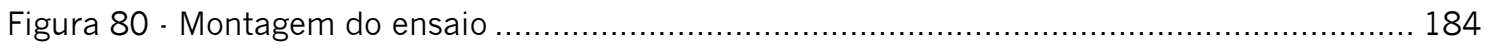

Figura 81 - Gráfico carga x deslocamento, em relação ao eixo de menor inércia ....................... 185

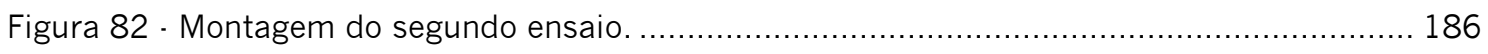

Figura 83 - Gráfico carga x deslocamento, em relação ao eixo de menor inércia ..................... 187

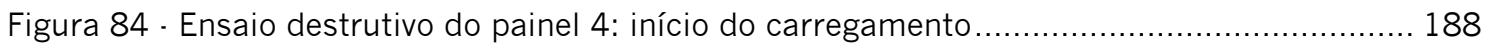

Figura 85 - Ensaio destrutivo do painel 4: instante da ruptura.................................... 188

Figura 86 - Ensaio destrutivo do painel 4: corpo de prova rompido .................................. 188

Figura 87 . Ensaio destrutivo do painel 4: ponto de ruptura ..................................... 189

Figura 88 - Gráfico carga x deslocamento do ensaio das lâminas de madeira ......................... 190

Figura 89 - Carga de ruptura das lâminas de madeira ................................................. 190

Figura 90 - Montagem do ensaio de ruptura das lâminas e início do carregamento................... 191

Figura 91 - Deformação sofrida pelo corpo de prova e início da ruptura................................ 191

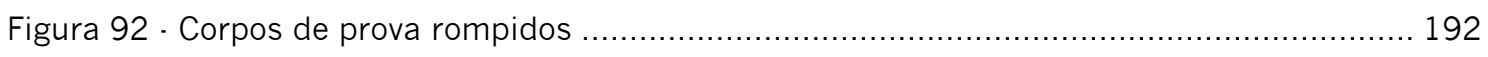

Figura 93 - Esquema do painel portante em madeira laminada cavilhada com revestimento do tipo deck de madeira, considerado para análise.

Figura 94 Planta baixa e corte esquemático dos modelos de unidade habitacional considerados

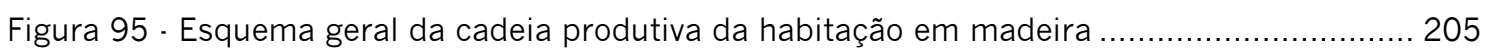


LISTA DE QUADROS

Quadro 1 - Ligações propostas por Cesar (2002) 14

Quadro 2 - Lista de componentes básicos pré-fabricados e seqüência de montagem - protótipo 1. .

Quadro 3 - Lista de componentes básicos pré-fabricados e seqüência de montagem - protótipo 2.

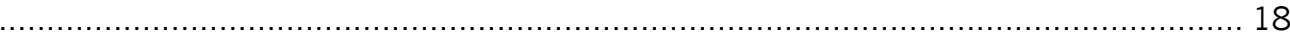

Quadro 4 - Dados de produtividade de 10 serrarias pesquisadas na região de Itapeva. 64

Quadro 5 - Simulação da produtividade de uma serraria da Região Sudoeste do Estado de S.Paulo.

Quadro 6 - Tipo, volume, valor de comercialização e destinação dos resíduos produzidos pelas serrarias da Região Sudoeste do Estado de São Paulo.

Quadro 7 -Viabilidade do uso da madeira de pinus na construção civil.

Quadro 8 - Exigências do usuário.

Quadro 9 - Classificação das funções de um componente de vedação vertical......

Quadro 10 - Condições de uso e agente de deterioração

Quadro 11 - Critérios propostos para a elaboração dos componentes construtivos para vedação vertical em madeira de terceira de pinus sp, em relação aos requisitos definidos pelas características locais.

Quadro 12 . Análise da concepção inicial dos painéis portantes para vedação vertical .............. 131

Quadro 13 - Tipos mais comuns de empenamento da madeira 141

Quadro 14 - Outros defeitos considerados pela norma brasileira para efeitos de classificação comercial da madeira.

Quadro 15 - Aspectos físicos das classes de qualidade consideradas pela ABPMEX............... 144

Quadro 16 - Classificação proposta para as tábuas de pinus......................................... 147

Quadro 17 - Resumo dos critérios de medição dos defeitos considerados para efeito de classificação da madeira.

Quadro 18 - Limitação proposta para os defeitos e características da madeira, para efeito de classificação visual da madeira serrada de pinus de terceira.

Quadro 19 - Processo de produção do painel laminado pregado .....

Quadro 20 - Seqüência das operações de aparelhamento da madeira com os respectivos equipamentos utilizados e resultado obtido em cada operação.

Quadro 21 - Seqüência de pré-montagem e furação das peças, com respectivos equipamentos utilizados e produtos obtidos.

Quadro 22 - Seqüência de preparação das cavilhas e respectivos equipamentos utilizados e resultados obtidos.

Quadro 23 - Avaliação do painel laminado cavilhado, de acordo com os critérios referentes às características locais.

Quadro 24 - Características do material ensaiado

Quadro 25 - Resultados obtidos para os ensaios realizados em relação ao eixo de menor inércia.

Quadro 26 - Resultados obtidos para os ensaios realizados em relação ao eixo de maior inércia.

Quadro 27 - Resultados obtidos para a determinação dos módulos de ruptura.

Quadro 28 . Fatores de produtividade para a floresta, serraria e unidade de pré-fabricação, necessários à produção de 50UH/ano. 
Quadro 29 - Estudo dos valores possíveis para comercialização da madeira de $1^{\text {a }}$ e/ou resíduos, no caso da venda da madeira ao preço máximo que viabilize a produção dos componentes.

Quadro 30 - Simulação do cenário de produção onde os usuários adquirem o equivalente em volume de toras, referente ao limite total do custo da madeira serrada de terceira, necessária à construção das $50 \mathrm{UH}$, com acordo de desdobro por parte da serraria.

Quadro 31 - Demonstrativo de cálculo do valor máximo a ser pago pela tora de pinus, colocada no pátio da serraria, para viabilizar a produção dos componentes.

Quadro 32 - Custos por hectare para implantação / manutenção de uma floresta de pinus resinífero em pequenos módulos rurais com espaçamento de 3,30 × 2,80 metros, e população inicial de 1.080 plantas

Quadro 33 - Custos por hectare para implantação / manutenção de uma floresta de pinus para usos múltiplos

Quadro 34 - Estudo sobre possíveis valores para os produtos do desdobro de toras de pinus provenientes de reposição florestal em pequenas propriedades rurais.

Quadro 35 - Programação para implantação de TUMP's, com ciclos de corte de 15 anos, visando a produção de $50 \mathrm{UH} / \mathrm{ano}$

Quadro 36 - Síntese do custo dos paineis para diferentes simulações 219

Quadro 37 - Síntese dos cenários de produção dos componentes construtivos para vedação vertical em madeira de terceira de pinus sp, avaliados de acordo com os ganhos e prejuízos de cada um dos agentes envolvidos. 
LISTA DE TABELAS

Tabela 1 - Estimativa da necessidade anual de plantio por segmento produtivo (x1000ha)..... 35

Tabela 2 - Relação dos dez municípios com áreas de Pinus mais expressivas no pólo de reflorestamento de Itapeva / Capão Bonito / Buri e sua participação em relação ao total do pólo.

Tabela 3 - Vinculação dos plantios de Pinus existentes no Pólo de Reflorestamento de Itapeva / Capão Bonito / Buri

Tabela 4 - Áreas de Pinus de acordo com as espécies e idades no Pólo de Reflorestamento de Itapeva / Capão Bonito / Buri....

Tabela 5 - Condições de manejo das áreas de Pinus no Pólo de Reflorestamento de Itapeva / Capão Bonito / Buri

Tabela 6 - Capacidade instalada das unidades de serrados no Brasil ..................................61 61

Tabela 7 . Propriedades mecânicas do Pinus sp e do Eucalyptus Citriodora ................................80 80

Tabela 8 - Possibilidades de aproveitamento da madeira: vantagens e desvantagens.................992

Tabela 9 - Composição do custo total de um edifício, segundo planos horizontais, verticais e instalações, em edificações habitacionais....

Tabela 10 . Classes de densidade definidas pela ASTM D245-93 ................................. 142

Tabela 11 . Classes visuais descritas na National Grading Rule ................................... 143

Tabela 12 . Dimensões padronizadas da madeira serrada de coníferas para uso geral. ............. 146

Tabela 13 - Limites relativos à área e diâmetro dos nós, em função da seção transversal das peças

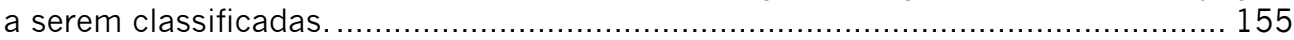

Tabela 14 - Resultado da classificação visual das peças.................................................... 159

Tabela 15 - Composição do custo de materiais necessários à produção de $1 \mathrm{~m}^{2}$ de parede em painel portante em Madeira Laminada Cavilhada (7,5×30cmxhvar), utilizando madeira de terceira de pinus, sem tratamento, revestida externamente com painel do tipo deck de madeira.

Tabela 16 - Composição do custo de materiais necessários à produção de $1 \mathrm{~m}^{2}$ de parede em alvenaria com bloco cerâmico 8 furos $(9 \times 14 \times 24 \mathrm{~cm})$, revestida com argamassa mista de cimento, areia e cal......

Tabela 17 - Composição do custo materiais necessários à produção de $1 \mathrm{~m}^{2}$ de parede em painel portante em Madeira Laminada Cavilhada, (5x30cmxhvar), utilizando madeira de terceira de pinus, sem tratamento, revestida externamente com um deck de madeira. 202

Tabela 18 - Composição do custo de de $1 \mathrm{~m}^{2}$ de parede em painel portante em Madeira Laminada Cavilhada $(7,5 \times 30 \mathrm{~cm} \times$ hvar $)$, utilizando madeira de terceira de pinus, sem tratamento, revestida externamente com painel do tipo deck de madeira...... 219

Tabela 19 - Composição do custo de produção de $1 \mathrm{~m}^{2}$ de parede em alvenaria com bloco cerâmico 8 furos $(9 \times 14 \times 24 \mathrm{~cm})$, revestida com argamassa mista de cimento, areia e cal...... 220 
Lista de ABReviaturas e SigLas

ABIMCI: Associação Brasileira das Indústrias de Madeira Processada Mecanicamente

ABNT: $\quad$ Associação Brasileira de Normas Técnicas

ABPM: $\quad$ Associação Brasileira de Produtores de Madeira

ABPMEX: $\quad$ Associação Brasileira de Produtores e Exportadores de Madeira

AWPA: $\quad$ American Wood Preservers Association

CCA: $\quad$ Arseniato de Cobre Cromatado

CCB: $\quad$ Borato de Cobre Cromatado

CDHU: $\quad$ Companhia de Desenvolvimento Habitacional e Urbano

CEPEA: Centro de Estudos Avançados em Economia Aplicada

CSTB: $\quad$ Centre Scientifique et Technique du Bâtiment - Paris

CSTC: $\quad$ Centre Scientifique et Technique de la Constrution

EESC: $\quad$ Escola de Engenharia de São Carlos

EMBRAPA: Empresa Brasileira de Pesquisa Agropecuária

FJP: $\quad$ Fundação João Pinheiro

HABIS: $\quad$ Grupo de Pesquisa em Habitação e Sustentabilidade

IBAMA: Instituto Brasileiro da Amazônia e do Meio Ambiente

IBDF: Instituto Brasileiro de Desenvolvimento Florestal

IBGE: Instituto Brasileiro de Geografia e Estatística

IF: Instituto Florestal

LaMEM: Laboratório de Madeiras e Estruturas em Madeira

MDF: $\quad$ Medium Density Fyberboard

MMA-SBF: Ministério do Meio Ambiente - Secretaria de Biodiversidade e Florestas

OSB: $\quad$ Oriented Strand Board

PIB: $\quad$ Produto Interno Bruto

PMVA: $\quad$ Produtos de Maior Valor Agregado

PNF: $\quad$ Plano Nacional de Florestas

PRONAF: Programa Nacional de Fortalecimento da Agricultura Familiar PROPFLORA: Programa de Plantio Comercial de Florestas

PSH: $\quad$ Plano de Subsídio à Habitação

REMADE: Revista da Madeira 
SBS: $\quad$ Sociedade Brasileira de Silvicultura

SEBRAE: $\quad$ Serviço Brasileiro de Apoio às Micro e Pequenas Empresas

SPIB: $\quad$ Southern Inspection Bureau

TCPO: $\quad$ Tabelas de Composição de Preços e Orçamentos

UNESP: $\quad$ Universidade Estadual Paulista Júlio de Mesquita Filho

UNIGRAN: Centro Universitário da Grande Dourados, MS 
SUMÁRIO

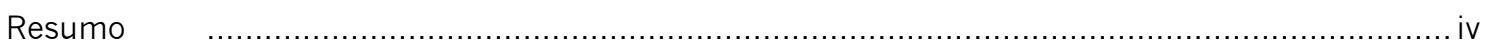

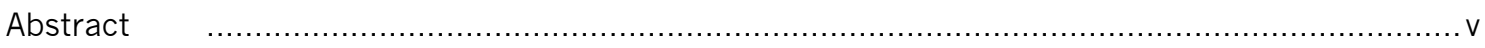

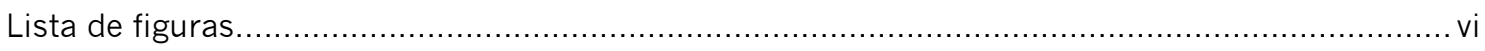

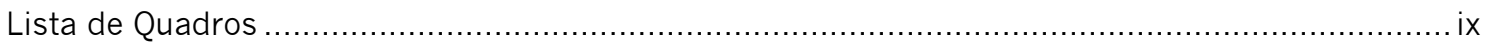

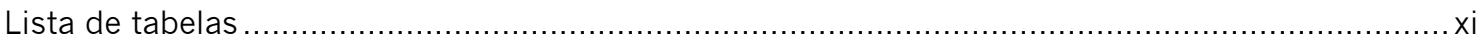

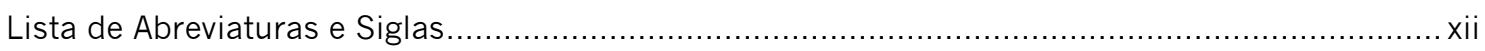

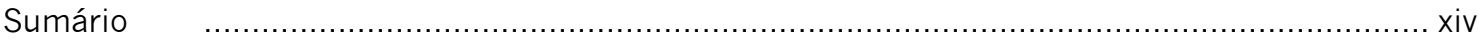

Capítulo 1: Contexto para o Desenvolvimento de Componente construtivo para habitação social em

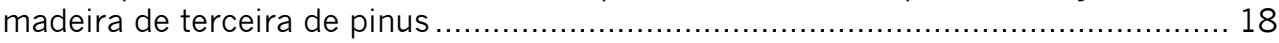

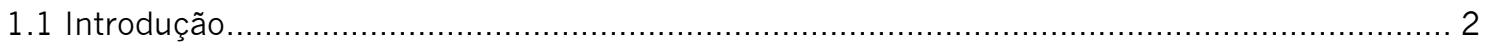

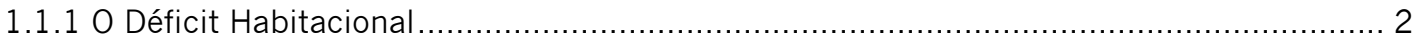

1.1.2 O Potencial Florestal e Madeireiro Brasileiro e da Região Sudoeste do Estado de São

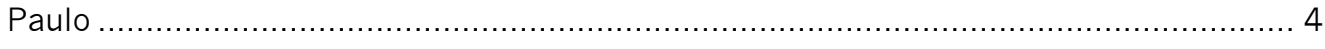

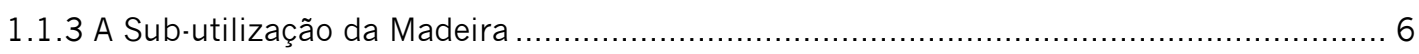

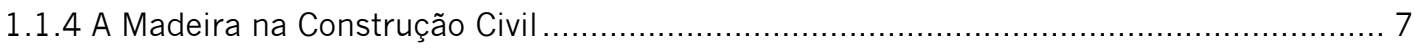

1.1 .5 A Madeira no Meio Acadêmico.......................................................... 10

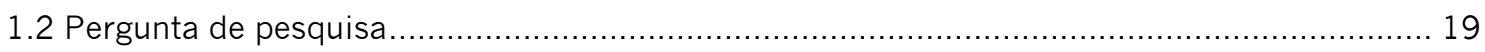

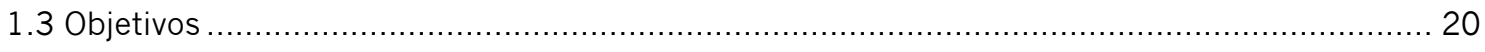

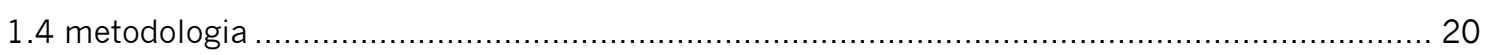

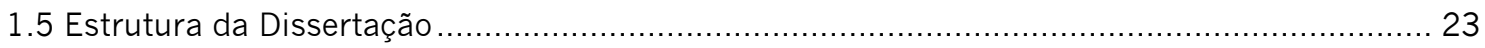

Capítulo 2: A Dinâmica da Produção da Madeira Serrada e Subprodutos na Região Sudoeste do

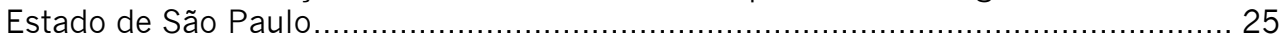

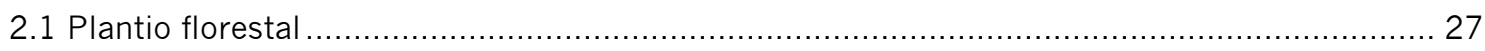

2.1.1 Plantios Florestais Brasileiros: Panorama Atual e Tendências ............................... 28

2.1.2 Os Plantios Florestais de Pinus na Região Sudoeste do Estado de São Paulo .............. 40

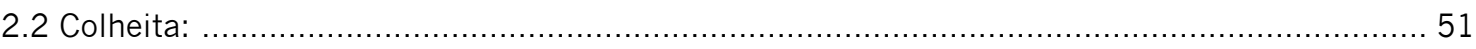

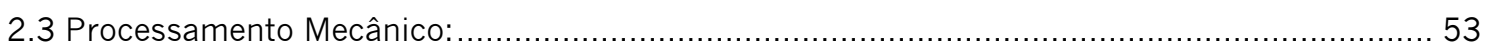

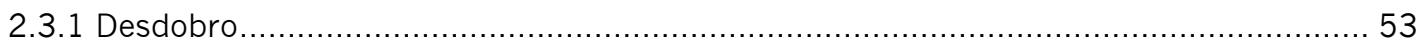

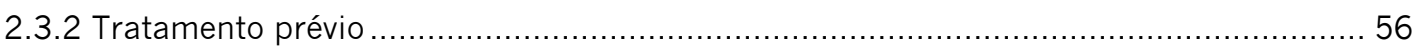

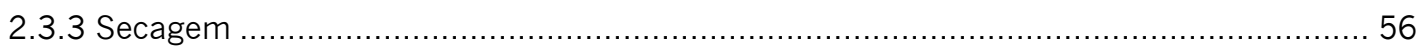

2.3.4 O Setor de Processamento Mecânico da Madeira Sólida. ...................................... 60

Capítulo 3: A Madeira Serrada de Pinus Como Material Construtivo Para Produção de Habitação

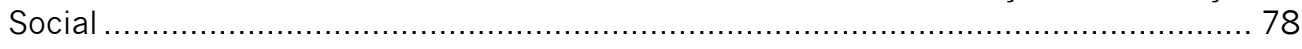

3.1 Aspectos Gerais da Madeira de Pinus Para a Construção ............................................. 79

3.2 Os Produtos e Subprodutos da Madeira Serrada de Pinus ......................................... 83

3.3 Potencialidades e Limites para a Utilização da Madeira de Terceira de Pinus sp para a Produção de Componentes para Habitação Social. 
Capítulo 4: Concepção e Desenvolvimento dos Componentes Construtivos Para Habitação Social Utilizando Madeira de Terceira de Pinus.

4.1 Escolha do Componente a Ser Desenvolvido .................................................... 96

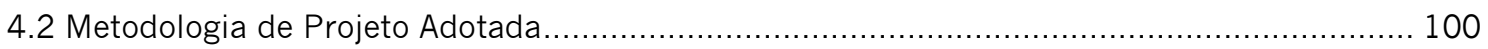

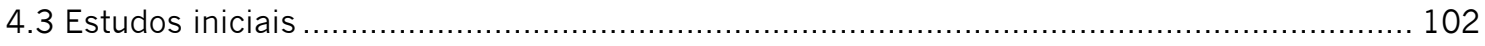

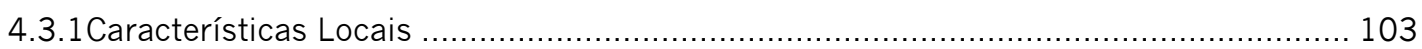

4.3.1.1 Renda Familiar Média Mensal....................................................... 103

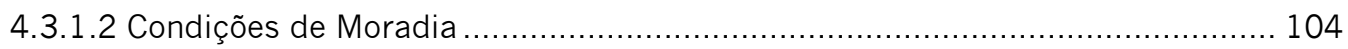

4.3.1.3 Região Produtora de Madeira .................................................... 107

4.3.1.4 Capacidade Tecnológica Instalada................................................. 108

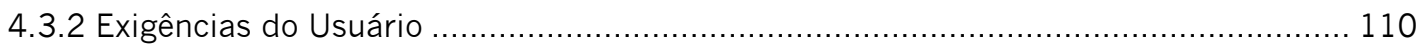

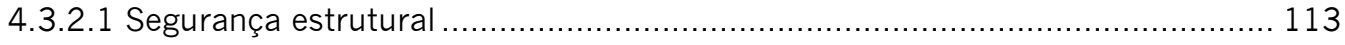

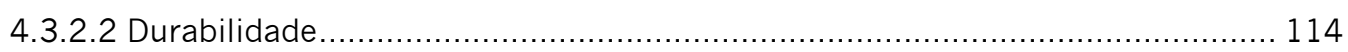

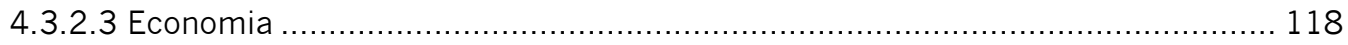

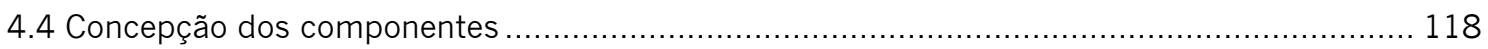

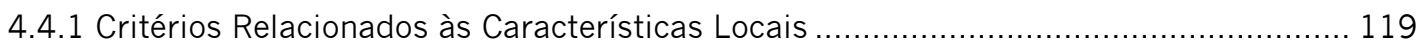

4.4.2 Critérios Relacionados à Segurança Estrutural ........................................ 123

4.4.3 Critérios Relacionados à Durabilidade ................................................. 125

4.4.4 Critérios Relacionados à Economia................................................... 125

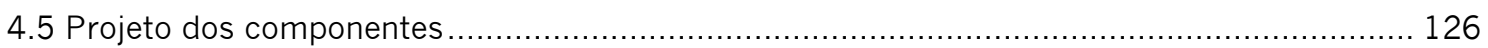

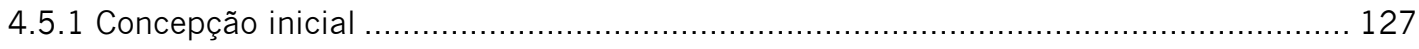

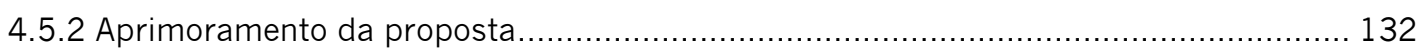

Capítulo 5: Produção e Avaliação dos modelos experimentais dos Componentes Construtivos Para Habitação Social Utilizando Madeira de Terceira de Pinus. ............................... 134

5.1 Classificação Visual da Madeira Serrada de Coníferas ............................................. 136

5.1.1 As regras Para Classificação Visual da Madeira Serrada de Coníferas ...................... 136

5.1.2 Critérios e Limites Para Classificação Visual da Madeira Serrada de Coníferas Propostos

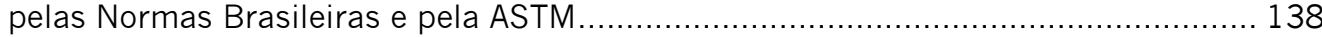

5.1.2.1 Classificação em Razão da Limitação dos Defeitos e Características das Peças de

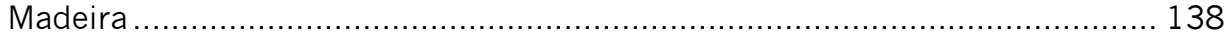

5.1.2.2 Classificação quanto ao uso ....................................................... 145

5.1.3 Adaptação do Método de Classificação Visual da Madeira Serrada de Coníferas Para Aplicação num Lote Proveniente de Engenheiro Maia, Itapeva, SP......................... 146

5.1.3.1 Classificação Quanto ao Uso: ...................................................... 147

5.1.3.2 Classificação em Razão da Limitação dos Defeitos e Características das Peças de Madeira ...................................................................................... 147

5.1.3.3 Critérios Para Limitação das Características de Crescimento e defeitos Apresentados pelas Peças de Madeira................................................ 154

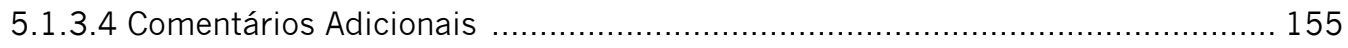

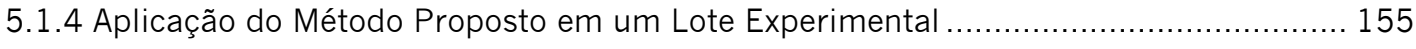

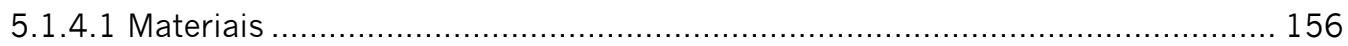

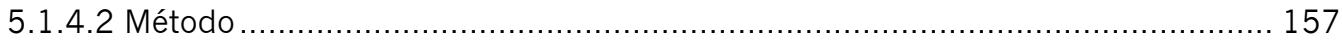


5.1.4.3 Resultados Obtidos 159

5.2 Processo de Produção do Modelo de Painel Laminado Pregado ..................................... 159

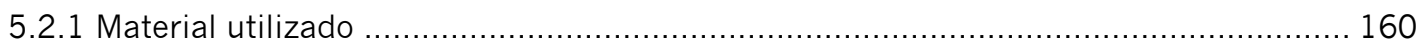

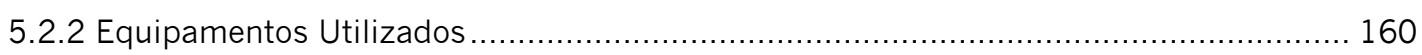

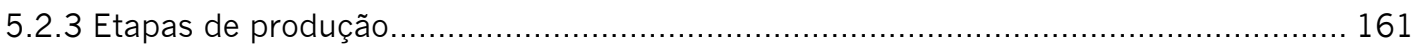

5.3 Produção dos Modelos de Painel Laminado Cavilhado ........................................... 163

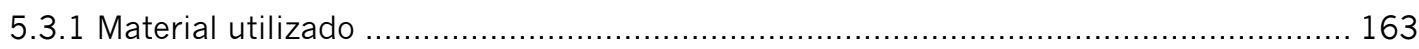

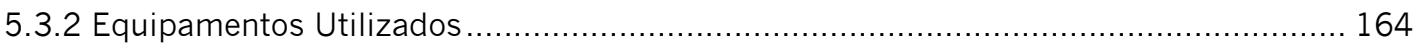

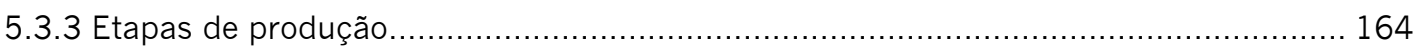

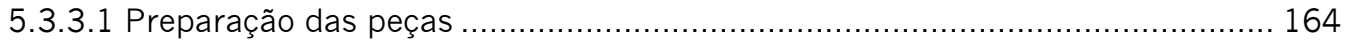

5.3.3.2 Preparação das cavilhas ................................................................ 170

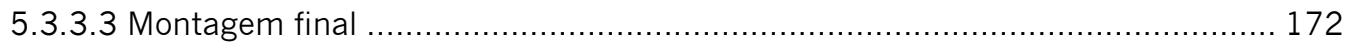

Capítulo 6: Avaliação dos Modelos Experimentais ............................................... 174

6.1 Avaliação do Atendimento aos Critérios Relacionados às Características Locais ................. 175

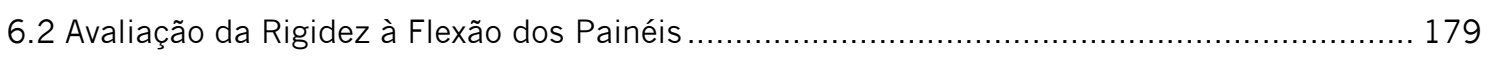

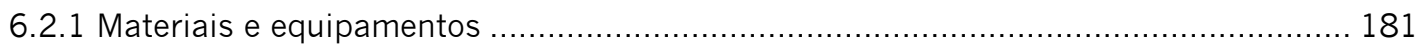

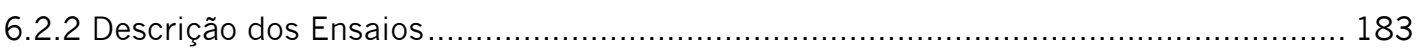

6.2.2.1 Ensaio 1: Resistência à Flexão em Relação ao Eixo de Menor Inércia .............. 183

6.2.2.2 Ensaio 2: Resistência à Flexão em Relação ao Eixo de Maior Inércia ............... 185

6.2.2.3 Ensaio 3: Determinação da Força de Ruptura...................................... 187

6.2.2.4 Ensaio 4: Determinação do Módulo de Elasticidade das Lâminas de Madeira . 189

6.2.2.5 Ensaio 5: Determinação da Força de Ruptura das Lâminas de Madeira........... 190

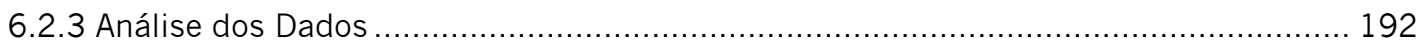

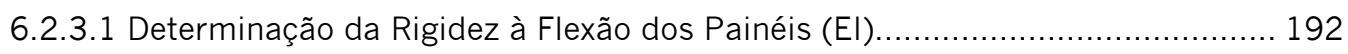

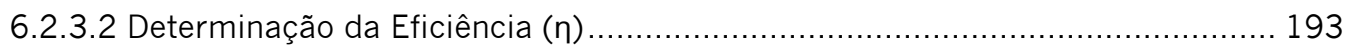

6.2.3.3 Determinação do Módulo de Ruptura (Mor)......................................... 194

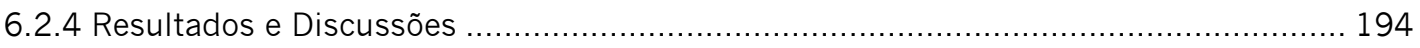

Capítulo 7: Análise da Viabilidade Econômica da Produção de Componentes Para Vedação Vertical Utilizando Madeira de Terceira de Pinus ................................................. 196

7.1 Alternativa 1: Redução do volume de madeira utilizado na produção dos componentes....... 201

7.2 Alternativa 2: Redução do Custo de Aquisição da Madeira .......................................... 202

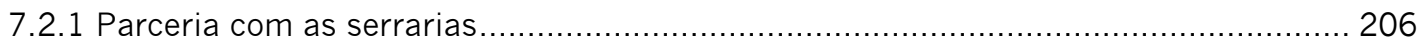

7.2.1.1 Cenário 1: Aquisição da madeira a um custo limite que garanta a competitividade

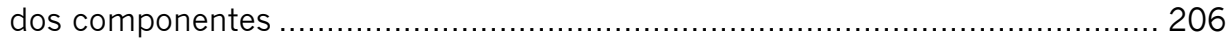

7.2.1.2 Cenário 2: Aquisição de volume de toras equivalente ao custo limite do total de madeira serrada de terceira necessária à produção das $50 \mathrm{UH}$..................... 207

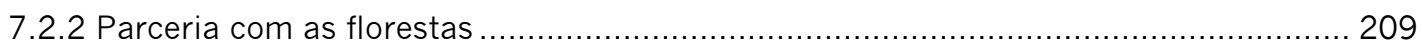

7.2.2.1 Cenário 3: Parcerias com os detentores das florestas .............................. 210

7.2.2.2 Cenário 4: Produção dos Componentes a Partir de Madeira Oriunda de Reposição Florestal em Pequenas Propriedades Rurais. 
Capítulo 8: Considerações Finais e Perspectivas de Continuidade 223

Referências Bibliográficas 233 